\title{
Impact behaviour of nylon-rubber blends: 5. Influence of the mechanical properties of the elastomer
}

\author{
R. J. M. Borggreve*, R. J. Gaymans and J. Schuijer \\ University of Twente, PO Box 217, 7500 AE Enschede, The Netherlands \\ (Received 13 April 1988; accepted 13 June 1988)
}

\begin{abstract}
Blends of $90 \mathrm{wt} \%$ nylon- 6 and $10 \mathrm{wt} \%$ impact modifier were prepared. As impact modifiers were used: EPDM (ethylene propylene diene monomer) rubber, EPM (ethylene propylene monomer) rubber, polyethylene, four poly (ether esters) and some commercial impact modifers. EPDM, EPM and polyethylene were functionalized with maleic anhydride. The mechanical properties of the impact modifiers were tested with both a torsion pendulum test and a tensile test. The notched impact strength of the blends was measured as a function of temperature. The relation between the mechanical properties of the elastomer and the impact behaviour of the elastomer-modified nylon- 6 was studied while taking into account the effect of the rubber particle size. The type of impact modifier was found to have a strong effect on the impact behaviour of the blend. The rubber particles do not toughen nylon- 6 by acting as stress concentrators.
\end{abstract}

(Keywords: nylon-rubber blend; impact toughness, rubber properties; particle size; toughening mechanism)

\section{INTRODUCTION}

In the large number of studies on toughening of polymers by rubber modification, the role of the mechanical properties of the rubber has hardly been dealt with. More attention is paid to the rheological behaviour of the rubber and/or the compatibility towards the polymer matrix in studies on the blending process in order to get a desired morphology, especially rubber particle size ${ }^{1-3}$. In order to gain more knowledge about the desired mechanical rubber properties, one has to know more about the function of the rubber particles in acting as impact modifiers. Merz ${ }^{4}$ and more recently $\mathrm{Kunz}$ and coworkers $^{5}$ suggested that the function of the rubber particles was to bridge the cracks and so prevent the crack growing to a catastrophic size. The increase in toughness of the multiphase polymer can be considered as the amount of elastic energy stored in the rubber particles during stretching which dissipates irreversibly when the particles rupture. This theory is not generally accepted because it cannot explain the phenomenon of stress whitening observed in most rubber-toughened plastics. Besides, the overview of Kinloch and Young ${ }^{6}$ illustrates that most studies on rubber-modified polymers show that principally the deformation mechanism in the matrix, enhanced by the presence of the second phase, improves the toughness.

In patents of Du Pont ${ }^{7,8}$ it is suggested that the modulus of the impact modifier must be one-tenth or less of that of the nylon matrix in order to be effective. This statement is supported by several authors according to the toughening mechanisms they propose in rubbermodified nylons. Hobbs ${ }^{9}$ as well as $\mathrm{Wu}^{10}$ claim that the effectiveness of rubber particles to toughen a polymer like nylon originates from the ability to generate stress concentrations around the particles in an applied stress

* Present address: DSM Research, PO Box 18, 6160 MD Geleen, The Netherlands field. Because of the difference in modulus between the dispersed phase and the matrix, the stress will be concentrated around the rubber particles which will lead to local nucleations of plastic deformation like crazing or shear banding. When the rubber particles are sufficiently close together the stress fields will overlap, which accounts for even an additional toughening effect.

Oxborough and Bowden ${ }^{11}$ calculated the stress concentration factors around low-modulus spheres in a rigid matrix. It turned out that when the ratio of the shear modulus of the dispersed phase to the shear modulus of the matrix $\left(G_{\mathrm{d}} / G_{\mathrm{m}}\right)$ is one-tenth, the maximum stress concentration factor (just above 2 at the matrix-particle interface) is almost reached. A further decrease of $G_{\mathrm{d}} / G_{\mathrm{m}}$ does not involve a further significant increase of the stress concentration factor. According to the toughening mechanisms based on stress concentration theories, all materials equal to or less than one-tenth of the nylon modulus may, in principle, have the same impact modifying effect. However, voids or rigid particles, though capable of generating stress concentrations, are said not to be effective because they are not able to act as crack stoppers $^{12}$ or to sustain imposed loads during the post-yield deformation ${ }^{13}$.

Bucknall $^{14}$ states that crosslinking of the rubber particles is desirable since during impact the rubber phase is subjected to very large tensile strains, giving a craze-like structure. In uncrosslinked polybutadiene, for example, molecular entanglements are unable to prevent rapid flow and fracture in response to an applied stress; at room temperature the rubber is far above its $T_{\mathrm{g}}$ and relaxation times are extremely short. A moderate degree of crosslinking allows the rubber to reach high strains by fibrillation and at the same time confers mechanical strength upon the fibrils.

In all these views a fast fracture of the rubber particles will cause a fast crack propagation preventing extensive plastic deformation in the matrix. On the contrary, 
Donald and $\mathrm{Kramer}^{15}$ and $\mathrm{Yee}^{16}$ propose a toughening mechanism for modified polymers with shear yielding as the main mode of plastic deformation, in which the function of the rubber particles is to generate voids. Rubber cavitation enables the relief of local hydrostatic tension. Soon after the development of some initial shear yielding, the triaxial stress is relieved and even relatively thick bulk specimens may behave as if the matrix were everywhere under plane stress conditions ${ }^{15}$. Excessive shear yielding can take place coupled with a large amount of energy absorption.

There is only little experimental work known in which the influence of the mechanical properties of the dispersed phase upon the impact behavior of blends is studied. $\mathrm{Dao}^{17}$ found that a lightly crosslinked EPDM (ethylene propylene diene monomer) rubber is a little bit more effective as impact modifier for polypropylene than an uncrosslinked EPDM. However, he did not report on the particle sizes used in the blends, which makes his conclusions not really valuable. The crosslinking will have consequences for the rubber viscosity too, which will affect the blending process and thus the rubber particle size. The particle size in turn strongly influences the impact behaviour of the blends ${ }^{18}$. However, lightly crosslinking EPDM did not seem to have any effect on the impact properties of polyamide-6/EPDM blends ${ }^{19}$. Tinker ${ }^{20}$ showed that an optimum crosslink density in natural rubber (cis-1,4-polyisoprene) exists for impact modification of polypropylene. Unfortunately, he also did not report whether the size of the dispersed phase was kept constant.

This paper aims at studying the relation between the mechanical properties of the impact modifier and the impact behaviour of rubber-modified nylon-6. Different types of rubber are used, keeping the rubber concentration in the blends constant $(10 \mathrm{wt} \%)$ and taking into account the effect of the particle size. As is shown ${ }^{10,19,21}$, the coupling agent is mainly important for the dispersion process and the concentration used will not be an essential variable in the impact studies.

When relating the mechanical properties of the rubber, measured at relatively low deformation rates, to the properties of the blends under impact conditions, a time-temperature superposition has to be taken into account. Therefore the Williams-Landel-Ferry ${ }^{22}$ equation is used to calculate the temperature shift $\Delta T$ in the modulus-temperature curve as the result of the relative change in time of testing, $t / t_{0}$ :

$$
\log \left(t / t_{0}\right)=-C_{1} \Delta T /\left(C_{2}+\Delta T\right)
$$

The constants $C_{1}$ and $C_{2}$ are found to be approximately 17.4 and 51.6 , respectively, for numerous polymers ${ }^{23}$.

\section{EXPERIMENTAL}

\section{Materials}

The matrix is nylon-6, obtained from Akzo: Akulon $\mathrm{M} 258, \eta_{\mathrm{rel}}=6.8$ in $96 \% \mathrm{H}_{2} \mathrm{SO}_{4}$.

As impact modifiers the following are used: (a) Keltan 740, EPDM (ethylene propylene dicyclopentadiene, $65 / 34 / 1 \mathrm{wt} \%$ ), supplied by DSM. (b) Dutral-CO 038FF, EPM (ethylene propylene, 70/30 wt\%), supplied by Montedison. (c) Stamylan LD 1808AN00, low-density polyethylene (PE), supplied by DSM. (d) Keltaflex N35, partially crosslinked thermoplastic elastomer, function- alized with maleic anhydride (MA), supplied by DSM. (e) XX1201, EPM (ethylene propylene $75 / 25 \mathrm{wt} \%$ ), functionalized with MA. (f) XX1301, EPM (ethylene propylene $75 / 25 \mathrm{wt} \%$ ), functionalized with MA. (g) XX1601(728), EPM (ethylene propylene $43 / 57 \mathrm{wt} \%$ ), functionalized with MA. The XX rubbers were supplied by Exxon. (h) Arnitel EL740, poly(ether ester), Shore hardness $D=74$. (i) Arnitel EL550, poly(ether ester), Shore hardness $D=55$. (j) Arnitel EM400, poly(ether ester), Shore hardness $D=40$. (k) Arnitel EL315, poly(ether ester), Shore hardness $D=31.5$. The 'Arnitel' thermoplastic elastomers were supplied by Akzo-Enka.

Keltan 740, Dutral and polyethylene were grafted with maleic anhydride in a Berstorff ZE $25 \mathrm{~mm}$ twin-screw extruder in the presence of bis(t-butylperoxyisopropyl)benzene (Perkadox 14, supplied by Akzo Chemie). The concentration of MA grafted on the impact modifiers was measured by both infra-red spectroscopy and potentiometric titration ${ }^{19}$. The thermoplastic Arnitel rubbers were used without chemical modification.

\section{Rubber testing}

The impact modifiers were compression moulded with a Lauffer to samples for testing. Tensile tests were performed on an Instron machine according to DIN $53455-4$ using a tensile speed of $250 \% \mathrm{~min}^{-1}$.

Shear moduli as a function of temperature were measured witha Myrenne torsion apparatus ATM 3 at a frequency of $1 \mathrm{~Hz}$ and a heating rate of $0.5^{\circ} \mathrm{Cmin}^{-1}$.

\section{Blend preparation}

Blends were prepared by compounding nylon- 6 successively with each of the (modified) elastomers in either a Kautex $40 \mathrm{~mm}$ single-screw extruder fitted with a $10 \mathrm{~cm}$ long cavity transfer mixing (CTM) head, or a Brabender $19 \mathrm{~mm}$ single-screw extruder or the Berstorff ZE 25 twin-screw extruder. The rubber concentration was kept constant: $10 \mathrm{wt} \%$. The blends were injection moulded on an Arburg Allrounder 221-35-250 to samples for impact testing.

\section{Molau test}

In order to investigate (qualitatively) if a graft polymer has been formed during the blending process the Molau test can be applied ${ }^{24,25}$. In our case the blend is placed in formic acid, which is a solvent for nylon-6 and a non-solvent for all the impact modifiers used. If there is no graft copolymer present to act as an emulsifier, the elastomer phase will separate and float on the solution. Then, the test result is called negative ${ }^{25}$. On the other hand, if a graft copolymer emulsifies the non-soluble component, a milky, colloidal suspension will arise, which means that the Molau test is positive.

\section{Scanning electron microscopy}

In order to analyse the average particle size in the blends, smooth surfaces of the samples were prepared using a Jung microtome, equipped with a glass knife and a liquid-nitrogen cooling unit. EP(D)M rubbers and PE were extracted from the surface by etching with boiling xylene overnight. The poly (ether ester) phase was removed from the surface by etching with boiling $p$-dichlorobenzene overnight. The samples were furnished with a gold layer and examined with a Jeol scanning electron microscope. 
Impact behaviour of nylon-rubber blends (5): R. J. M. Borggreve et al.
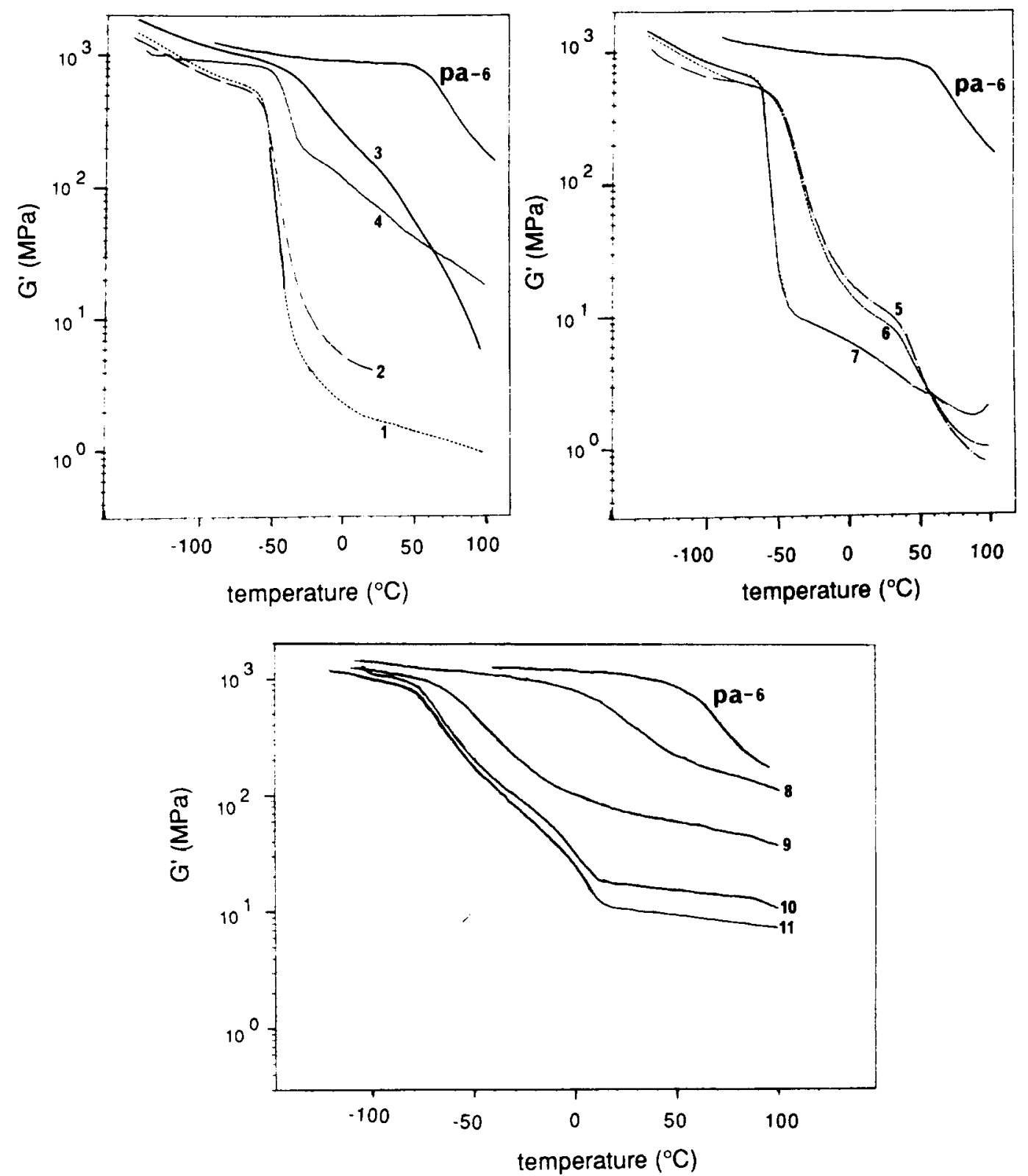

Figure $11 \mathrm{~Hz}$ shear modulus versus temperature of the (modified) elastomers and low-modulus thermoplastics: (1) EPDM-Keltan 740; (2) EPM-Durtral; (3) PE; (4) Keltaflex N35; (5) XX1201; (6) XX1301; (7) XX1601; (8) Arnitel EL740; (9) Arn EL550; (10) Arn EM400; (11) Arn E315

From photomicrographs the particle size distribution could be obtained.

\section{Impact testing}

Injection-moulded samples of the blends were dried before testing for $24 \mathrm{~h}$ at $110^{\circ} \mathrm{C}$ in a vacuum oven. The notched Izod impact strength was measured with a Z wick impact testing machine according to ISO $180 / 1 \mathrm{~A}$. The test temperature varied from -40 up to $80^{\circ} \mathrm{C}$. The average values of at least five tests are reported.

\section{RESULTS}

\section{Rubber properties}

MA was found to be necessary to disperse EPDM rubber sufficiently finely in a polyamide melt. In a previous paper, however, it has been observed that the concentration of maleic anhydride coupled to the elastomer hardly influences either the dispersion process or the impact behaviour of the blends ${ }^{20,21}$. In Table 1 the
MA concentration of the impact modifiers, which was obtained from infra-red spectroscopy, is given.

In Figure 1 the shear moduli of the (modified) impact modifiers have been plotted against the temperature. The curves can be transformed to the conditions for impact testing by using the WLF equation. Therefore a relationship must be established between the frequency $f$ of the torsion pendulum test and the time to fracture $t_{\mathrm{f}}$. The following relationship has been proved to be suitable ${ }^{26}$ :

$$
t_{\mathrm{f}}=1 /(2 \pi f)
$$

According to this equation a frequency of $1 \mathrm{~Hz}$ corresponds to a time to fracture of $160 \mathrm{~ms}$. The time to fracture in an impact test is estimated to be $0.5 \mathrm{~ms}^{27.28}$. Thus, with equation (1) it can be deduced that the shear modulus curves of Figure 1 shift approximately $9^{\circ} \mathrm{C}$ forwards when used for impact conditions. In Figure 2 the stress-strain behaviour of the impact modifiers at room temperature and a strain rate of $250 \% \mathrm{~min}^{-1}$ is given. 
Table 1 Concentration of maleic anhydride coupled with the elastomers and with PE

$\begin{array}{llllllll}\text { Rubber } & \text { Keltan 740 } & \text { Dutral } & \text { PE } & \text { Keltaflex XX1201 } & \text { XX1301 } & \text { XX1601 } \\ \text { [MA] (wt\%) } & 0.5 & 0.4 & 0.2 & 0.7 & 0.7 & 0.7 & 0.9\end{array}$
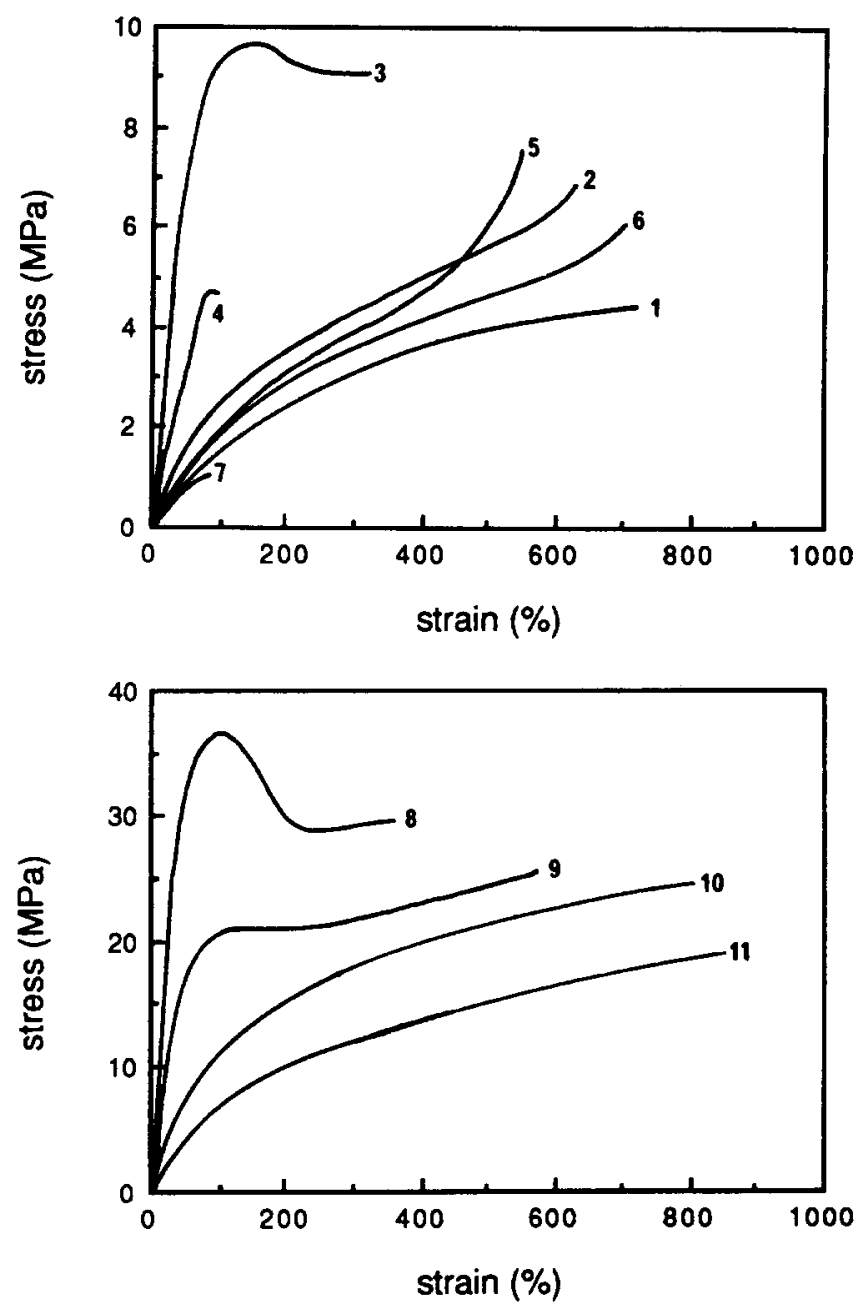

Figure 2 Stress-strain diagrams of: (1) EPDM-Keltan 740; (2) EPM-Dutral; (3) PE; (4) Keltaflex; (5) XX1201; (6) XX1301; (7) XX1601; (8) Arnitel EL740; (9) Arn EL550; (10) Arn EM400; (11) Arn E315

\section{Blending}

Blends were made from $90 \mathrm{wt} \%$ nylon- 6 and $10 \mathrm{wt} \%$ of one of the (modified) elastomers. Table 2 shows the impact modifier and extruder used as well as the weight-average particle size in the blend. All blends, M1 to M11, scored positively in the Molau test, indicating that graft copolymers are formed at the nylon-rubber interface.

The MA-modified polymers, M1 to M7, react with nylon- 6 during the blending process in the extruder as described elsewhere ${ }^{19}$. The thermoplastic Arnitel elastomers, though not modified with MA, are obviously still reactive towards nylon- 6 . When blending a poly(ether ester) with the nylon, an ester-amide interchange reaction may occur. Pillon, Utracki et al. ${ }^{29,30}$ demonstrated experimentally the occurrence of this reaction in the blending process of poly(ethylene terephthalate) and polyamide-6,6. Since blends M8 to M11 scored postively in the Molau test and considering the small average particle size in the blends, we believe that compatibilization between the two phases was assured by an interface reaction. Remarkably, each modifier could be dispersed below a size of $1 \mu \mathrm{m}$, independent of the blend apparatus used.

\section{Impact properties}

The notched Izod impact strengths of the blends are given as functions of temperature in Figure 3. In most blends, at a certain temperature a discontinuous jump in impact energy can be observed, which is called the brittle-tough (BT) transition. Below this temperature, plastic deformation mainly takes place before crack initiation, whereas above the BT temperature plastic deformation also occurs as the crack propagates. This has been discussed in more detail elsewhere ${ }^{18}$. In some blends the BT transition coincides with the $T_{\mathrm{g}}$ of the nylon, at which temperature the yield stress decreases by several orders ${ }^{31}$.

Figures $3 a-d$ affirm earlier findings ${ }^{18}$ that within one type of blend the BT temperature decreases with decreasing particle size, implying an improved impact behaviour. Conspicuously, the blends with EPM as impact modifier (M2a, M5, M6 and M7) show a maximum in impact strength above the BT temperature whereas the impact energy of the other blends increases monotonically with temperature. Above the BT temperature the impact energy of the EPM blends is not as high as that of the EPDM, Keltaflex or Arnitel blends, which means that during crack propagation less plastic deformation took place.

The impact strength of nylon- 6 is only moderately improved by blending with the thermoplastic Arnitel rubbers. Nevertheless, from Figure $3 f$ it seems that, while keeping the particle size fairly constant, the impactmodifying effect increases when elastomers with lower Shore hardness $D$ were used.

\section{DISCUSSION}

\section{Influence of rubber properties}

When comparing different types of impact modifiers, differences between the average particle size, and consequently the interparticle distance ${ }^{18}$, have to be taken into account. Therefore, in Figure 4 the BT temperatures of

Table 2 Type of rubber and extruder used for the blending process. Weight-average particle size of the dispersed phase

\begin{tabular}{llll}
\hline Blend & Rubber & Extruder & $\begin{array}{l}\text { Particle size } \\
(\mu \mathrm{m})\end{array}$ \\
\hline M1a & K740 & Kautex & 0.29 \\
M1b & K740 & Kautex & 0.46 \\
M1c & K740 & Brabender & 0.94 \\
M2a & Dutral & Kautex & 0.23 \\
M2b & Dutral & Brabender & 0.49 \\
M3a & PE & Berstorf & 0.18 \\
M3b & PE & Kautex & 0.49 \\
M4a & Kflex & Kautex & 0.15 \\
M4b & Kflex & Brabender & 0.29 \\
M5 & XX1201 & Kautex & 0.25 \\
M6 & XX1301 & Kautex & 0.16 \\
M7 & XX1601 & Kautex & 0.14 \\
M8 & Arn740 & Kautex & 0.25 \\
M9 & Arn550 & Kautex & 0.25 \\
M10 & Arn400 & Kautex & 0.14 \\
M11 & Arn315 & Kautex & 0.28 \\
\hline
\end{tabular}



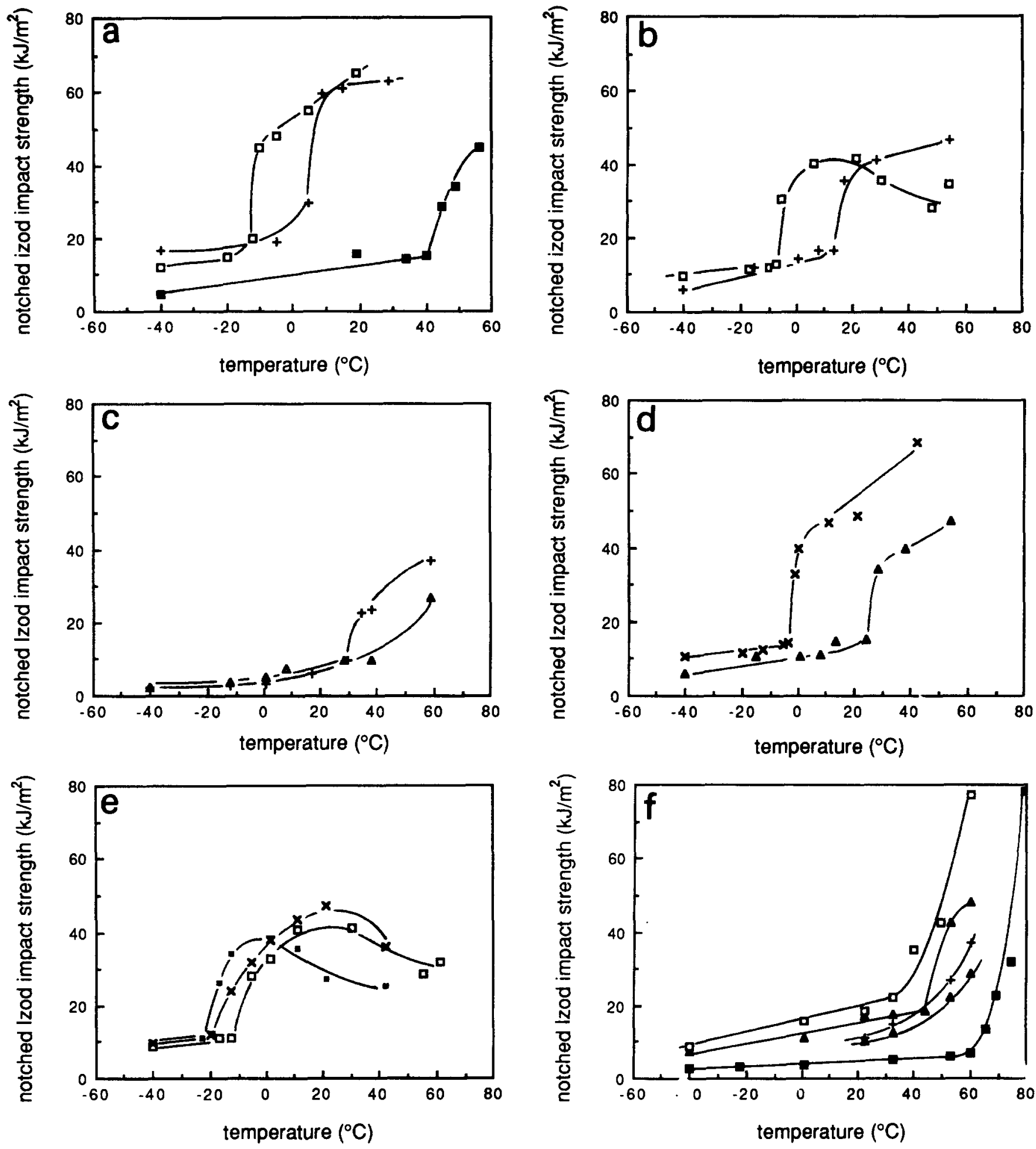

Figure 3 Notched Izod impact strength versus temperature: (a) Keltan 740 blends: ( $\square$ ) M1a; (+) M1b; ( $\square$ ) M1c. (b) Dutral blends: ( $\square$ ) M2a; (+) M2b. (c) PE blends: (+) M3a; ( $\triangle$ ) M3b. (d) Keltaflex blends: (×) M4a; (A) M4b. (e) XX rubber blends: ( $\square$ ) M5; ( $\times$ ) M6; ( $\square$ ) M7. (f)

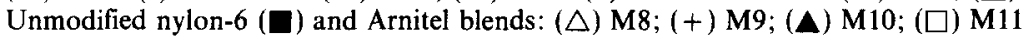

the blends are plotted against the weight-average particle sizes in order to avoid this problem. Besides the influence of particle size, Figure 4 shows that the BT temperature decreases in the order: PE-Arnitel-Keltaflex-EPM (both Dutral and XX-rubbers)-EPDM. Figure 4 thus contradicts the idea that the interparticle distance is the only parameter which determines the impact behavior of nylon-rubber blends ${ }^{10,32}$, but gives evidence of a marked influence of the type of rubber used. Although it is properly not allowed to relate the stress-strain curves (low deformation rate) to the impact-modifying effects (high deformation speed) of the elastomers, it seems that the differences between the effects of the modifiers cannot be explained by differences in strength. Confirming what was shown in the previous paper ${ }^{19}$, neither the tensile strength nor the elongation at break of the impact modifier seem to be the governing factor in the toughening process.

Interestingly, the BT temperature of the blends decreases on first sight in the direction where the modulus of the 


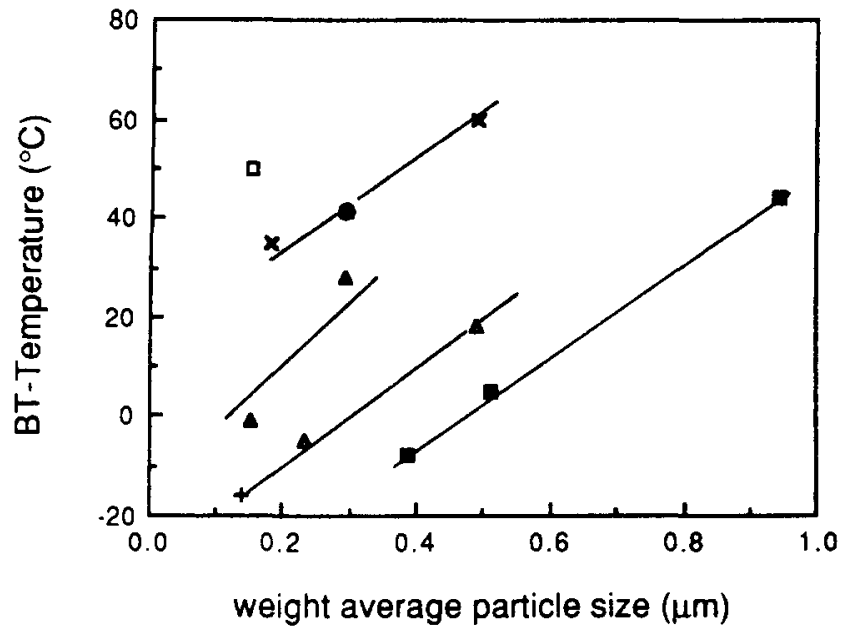

Figure 4 BT temperature as a function of the weight-average particle size for different types of impact modifier: $(\square)$ EPDM; $(\triangle)$ Dutral; (x) PE; (A) Keltaflex; (+) XX1201; ( $\square$ ) Arn400; (○) Arn315

impact modifier (Figure 1) decreases: PE-KeltaflexEPM-EPDM. However, although among the poly(ether esters) themselves a similar trend can be recognized (a slightly increased impact strength with decreasing modulus), the effects of the relatively low-modulus Arnitels (EM400 and E315) do not fit into the total picture.

\section{Rubber particles as stress concentrators}

Figure 1 shows that the moduli of all the impact modifiers, except PE and Arnitel EL 740, are over a broad temperature range clearly below one-tenth of the nylon modulus, even when the time-temperature shift is applied. Nevertheless, studying Figures 3 and 4 one can see that below one-tenth of the nylon modulus the nylon impact-modifying effect still may change with the type of modifier. For example, both the poly(ether ester) (Arnitel E315) particles in blend M11 and the EPDM particles in blends M1a, M1b and M1c are capable of generating at room temperature (RT) stress concentrations in the nylon matrices when in an applied stress field, since the moduli of both type of modifiers are well below one-tenth of the nylon modulus at RT. So both modifiers follow the criterion of Oxborough and Bowden ${ }^{11}$. However, at RT the impact strengths of the EPDM blends are much higher than the impact strength of blend M11. The assumption that the only function of the modifier particles should be the generation of stress concentrations in order to nucleate shear bands is therefore unjustified.

\section{Rubber particles as nuclei of voids}

The influence of the rubber modulus on the impact behaviour of the blends can also be related to the ability of the rubber to cavitate. In front of a propagating crack in the nylon-rubber specimen, a triaxial stress state exists. It is known from the work of $\mathrm{Gent}^{33}$ that, in this particular state, the stress needed for rubber cavitation decreases with decreasing elastic modulus. The process of voiding (and relieving the hydrostatic pressure) is therefore favoured in nylon-6, modified with a rubber with lower modulus. Accordingly, excessive plastic deformation during crack propagation may occur at low temperature when the modulus of the impact modifier decreases.
Yet, some phenomena remain unexplained. First, there is the relatively low impact strength and the occurrence of a maximum in impact energy above the BT temperature of the EPM blends. Secondly, the effects of some poly(ether esters) (Arnitel E315 and EM400) are less than expected on the grounds of their relatively low moduli. However, it should be noted that since the Arnitels are not real elastomers, they probably will not fit in Gent's model. In the next paper the influence of rubber properties on the voiding processes in nylon-rubber blends is studied more closely. It will be shown that the moderate impact-modifying effect of the low-modulus Arnitels is not due to the absence of maleic anhydride.

\section{CONCLUSIONS}

The impact behavior of nylon- 6 can be improved by adding a second phase. The impact-modifying effect varies with the type of modifier, proving that the interparticle distance is not the only factor which determines the impact behaviour of nylon-rubber blends. Blends of nylon-6 and an EPM rubber have an optimum in impact strength when increasing the temperature while the impact strength of blends of nylon-6 and EPDM or Keltaflex increases monotonically with temperature.

The experimental results do not support the idea that rubber particles toughen nylon only by acting as stress concentrators. It looks as though the impact behaviour gradually improves with decreasing modulus of the impact modifier (PE-Keltaflex-EPM-EPDM), although the group of thermoplastic poly(ether ester) elastomers is an exception here. The suggestion that the impact modifier, in order to be effective, must have an elastic modulus below one-tenth of the matrix modulus (or an elastic modulus below $1410 \mathrm{~kg} \mathrm{~cm}^{-2}$ (ref. 8)) is disproved by the present work. Another indication for this is that blends of nylon- 6 and a soft poly(ether ester), in spite of a small particle size and a relatively low modulus of the impact modifier, have only moderate impact behaviour. This phenomenon is discussed in the next paper.

Nevertheless, the mechanism of rubber cavitation and hydrostatic pressure relief seems to be more consistent with the experimental results than the mechanism based on rubber particles generating stress fields and stress field overlaps.

\section{ACKNOWLEDGEMENTS}

This work is part of the research programme of the University of Twente and was financially supported by the Netherlands Technology Foundation (STW) and by the DSM Research Company.

\section{REFERENCES}

1 Wu, S. Polym. Eng. Sci. 1987, 27(5), 335

2 Karger-Koscis, J., Kallo, A. and Kuleznev, V. N. Polymer 1984, 25, 279

3 D'Orazio, L., Mancarella, C., Martuscelli, E., Casale, A., Fillippi, A. and Speroni, F. J. Mater. Sci. 1986, 21, 989

4 Merz, E. H., Claver, G. C. and Baer, M. J. Polym. Sci. 1956, 22, 325

5 Kunz, S., Beaumont, P. W. R. and Ashby, M. F. J. Mater. Sci. $1980,15,1109$

6 Kinloch, A. J, and Young, R. J. 'Fracture Behaviour of Polymers', Elsevier Applied Science, London, 2nd Edn., 1985

$7 \quad$ GB patent 998439

$8 \quad$ US patent 4174358 
Impact behaviour of nylon-rubber blends (5): R. J. M. Borggreve et al.

Hobbs, S. Y., Bopp, R. C. and Watkins, V. H. Polym. Eng. Sci. $1983,23,1983$

Wu, S. Polymer $1985,26,1855$

Oxborough, R. J. and Bowden, P. B. Phil. Mag. 1974, 30, $17 \mathrm{l}$

Owen, A. B. J. Mater. Sci. 1979, 14, 2521

Kinloch, A. J. and Young, R. J. 'Fracture Behaviour of Polymers', ref. 6, pp. 427-8

14 Bucknall, C. B. in 'Polymer Blends' (Eds. D. R. Paul and S. Newman), Academic Press, New York, 1978, p. 91

Donald, A. M. and Kramer, E. J. J. Mater. Sci. 1982, 17, 1765

Yee, A. F. Proc. Conf. 'Toughening of Plastics', London, 1985

Dao, K. C. J. Appl. Polvm. Sci. 1982, 27, 4799

Borggreve, R. J. M., Gaymans, R. J., Schuijer, J. and Inge Housz, J. F. Polymer 1987, 28, 1489

Borggreve, R. J. M. and Gaymans, R. J. Polymer 1989, 30, 63 Tinker, A. J. Proc. Conf. 'Toughening of Plastics', London, 1985 Borggreve, R. J. M., Gaymans, R. J. and Luttmer, A. R. Macromol. Chem. Macromol. Symp. 1988, 16, 195
22 Williams, M. L., Landel, R. F. and Ferry, J. D. J. Am. Chem. Soc. 1955, 77, 3701

23 Kenner, V. H. in 'Failure of Plastics' (Eds. W. Brostow and R. D. Corneliussen), Hanser, Munich, 1986, p. 8

Molau, G. E. Kolloid Z. Z. Polym. 1970, 238, 493

Illing, G. Angew. Makromol. Chem. 1981, 95, 83

Menges, G. and Boden, H. E. in 'Failure of Plastics', ref. 23, p. 169

Luttmer, A. R. MSc thesis, University of Twente, 1987

28 Merle, G., Yong-Sok, O., Pillot, C. and Sautereau, H. Polym. Testing 1985, 5, 37

29 Pillon, L. Z. and Utracki, L. A. Polym. Eng. Sci. 1984, 24, 1300

30 Pillon, L. Z., Lara, J. and Pillon, D. W. Polym. Eng. Sci. 1987, 27(13), 984

Borggreve, R. J. M. and Gaymans, R. J. Polymer 1988, 29, 1441 Wu, S. Polymer. Prepr. (ACS) 1987, 28(2), 179

Gent, A. N. in 'Science and Technology of Rubber' (Ed. F. R. Eirich), Academic Press, New York, 1978, p. 419 